\title{
Influence of Niobium Addition on Microstructure and Machinability of High Chromium Cast Iron
}

\author{
Anderson Edson da Silva * (1), Ismael Nogueira Rabelo de Melo ${ }^{\text {(1), Ivete Peixoto Pinheiro }}$, \\ Leonardo Roberto da Silva ${ }^{a}$ \\ ${ }^{a}$ Centro Federal de Educação Tecnológica de Minas Gerais, Departamento de Engenharia de \\ Materiais, Belo Horizonte, MG, Brasil. \\ ${ }^{b}$ Instituto Federal de Minas Gerais, Ibirité, MG, Brasil.
}

Received: September 18, 2020; Revised: April 06, 2021; Accepted: June 11, 2021

\begin{abstract}
High Chromium Cast Iron (HCCI) is mostly utilised in environments under severe abrasion and corrosion wear conditions, and research on this material with added niobium obtained positive results regarding wear resistance. The casting process has surface finish and dimensional accuracy limitations compared to machining processes. There are too few studies about HCCI machinability and no one about HCCI with niobium additions. HCCI machinability studies may allow new applications for this material when excellent surface finish and high dimensional accuracy are required. This study analyses the influence of $0.5 \% \mathrm{Nb}$ addition on the microstructure and machinability of a HCCI alloy with $25.6 \%$ $\mathrm{Cr}$ and $3.2 \% \mathrm{C}$. The samples were heat treated and subsequently machined in dry cutting conditions. Annealing was used to facilitate the pre-machining of the samples, which were later quenched and tempered. Microstructure and hardness were analysed at each stage of the heat treatment. The material was machined after tempered using polycrystalline cubic boron nitride ( $\mathrm{pcBN})$ tools. The alloys solidified in the hypereutectic condition. The addition of niobium reduced the hardness and carbide volumetric fraction, increased the service life of the cutting tools in all tests, provided better surface finishing and modified the wear mechanisms.
\end{abstract}

Keywords: Machining, High Chromium Cast Iron (HCCI), Niobium, pcBN tool, Wear mechanisms, Tool service life.

\section{Introduction}

High Chromium Cast Irons (HCCI) are known for their abrasion wear resistance, are widely used and several studies have been conducted due to their metallurgical characteristics and wear behaviour ${ }^{1}$. Gutnichenko et al. ${ }^{2}$ highlighted that HCCI has high wear resistance, becoming a material used for applications in aggressive environments where high abrasion, erosion and corrosion resistance are required. Examples of applications are slurry pump volutes and rotors, crushers, crusher grids, gravel pumps and dredgers.

HCCI can present hypoeutectic, eutectic, and hypereutectic microstructures. Hypoeutectic alloys can be characterised by the presence of austenite dendrites. These dendrites are surrounded by a eutectic formed essentially by austenite and carbides. The structure of eutectic alloys is characterised by lamellae formed by the eutectic, whereas in the hypereutectic structure, the presence of large hexagonal primary carbides can be detected ${ }^{1}$.

Heat treatment is used to modify the matrix microstructure, and the best wear resistance results are obtained with martensitic matrix ${ }^{3}$. Penagos et al..$^{4}$ point out that the addition of niobium $(\mathrm{Nb})$ can lead to significant gains in the wear resistance of HCCIs and that adding approximately $1 \% \mathrm{Nb}$

*e-mail: andersonsilva@cefetmg.br may result in good cost benefits for industrial applications. Bouhamla et al..$^{5}$ achieved a $60 \%$ reduction in mass loss for a $\mathrm{HCCI}$ alloy containing $15 \% \mathrm{Cr}, 2.31 \% \mathrm{C}$, and added $0.5 \% \mathrm{Nb}$; above this level, addition of $\mathrm{Nb}$ did not bring significant gains.

According to Oliveira et $\mathrm{al} .{ }^{6}$, turning materials with a high fraction of hard particles in their microstructure, such as HCCI, results in high wear rates and damage to the tool cutting edges. According to Amorim et al. ${ }^{7}$, annealing is important in HCCI when the goal is to achieve hardness to ensure reasonable machinability; however, the highest wear resistance is achieved in the hardened condition.

Zhou and Andersson ${ }^{8}$ noted that tool wear varies significantly as a function of the amount of carbides in the material and the process temperature. Tool wear is mainly caused by the carbide eliminated by the tool flank, thus increasing wear as a function of the carbide content. Chen et al. ${ }^{9}$, found that pure $\mathrm{cBN}$ tools offer poorer results than those of mixed pcBN tools in the machining of HCCIs.

Niobium addition to HCCIs may provide interesting results regarding wear resistance, but little is known about the effects of adding niobium on the machinability of these materials. According to Chen et al. ${ }^{10} \mathrm{pcBN}$ tools are considered the main cutting tools in hard turning and offer a quality similar to grinding. Hard turning has become an 
alternative process in the manufacturing of hardened materials and with the development of new materials for cutting tools, it is possible to eliminate the cutting fluid in hard turning, reducing costs, and improving the process flexibility ${ }^{11,12}$. Silva et al. ${ }^{13}$ emphasize the cutting fluid use brings gains of pcBN tool life in HCCI machining, but machining is possible without it, so the cost benefit of its use must be analyzed.

In this research, a hardened HCCI alloy, with and without the addition of niobium, was developed and characterised. The characterisation of the samples was achieved by X-ray diffraction (XRD), scanning electron microscopy (SEM), hardness testing and measurement of the carbide volumetric fraction $(\mathrm{CVF})$. Dry turning was performed with pcBN tools at 100,150 and $200 \mathrm{~m} / \mathrm{min}$ cutting speeds. Tool service life, wear mechanisms and roughness were also analysed. Tool life and roughness improve were observed in alloys with niobium addition. This probably occurred because of carbides volumetric fraction reduction, hardness reduction and microstructure refinement.

\section{Experimental Procedure}

The metallic load used in the casting process consisted of pieces of an ore slurry pump rotor, manufactured from HCCI ASTM A $5322^{14}$ Class III, type A. Niobium was incorporated into the alloy using a Fe-Nb alloy with $66 \% \mathrm{Nb}$ and $21.5 \mu \mathrm{m}$ mean particle size. Melting was carried out in a $300 \mathrm{~kg}$ capacity induction furnace, in a single batch. Half of the charge was poured without the addition of niobium, and $\mathrm{Fe}-\mathrm{Nb}$ alloy was added to the other half, aiming at a $0.5 \%$ $\mathrm{Nb}$ content. The dissolution time was $15 \mathrm{~min}$, reaching an approximate dissolution rate of $90 \%$. Both alloys were poured at $1550 \pm 50^{\circ} \mathrm{C}$. Table 1 shows the reference alloy specified by ASTM A532 standard ${ }^{14}$, and the cast alloys, being alloy A (without addition of niobium) identified as $0 \% \mathrm{Nb}$, and alloy B (with addition of niobium) identified as $0.5 \% \mathrm{Nb}$.

The moulds were made from synthetic sand, capable of holding 6 samples. For the finishing and removal of irregularities, a $1.5 \mathrm{~mm}$ allowance was added on each surface of the sample. The samples were cylindrical, and after pre-machining, the following dimensions were obtained: $96 \mathrm{~mm}$ external diameter, $40 \mathrm{~mm}$ thickness and a $26 \mathrm{~mm}$ diameter through hole in the centre of the samples, the sample design can be seen in Figure 1. The machining was carried out by face turning operation. A similar sample model was used by Diniz and Oliveira ${ }^{15}$ and Oliveira et al. ${ }^{16}$ for turning hardened steel. Oliveira et al. ${ }^{6}$ also used a similar sample format in the machining of HCCI, but in the as-cast state. This geometry aims at higher efficiency and material yield in the experiments, resulting in a constant geometry in all tests stages, which increases tests reliability, allowing samples amount used reduction.

After cooling, the samples were separated, grit blasted for cleaning and taken to the furnace for annealing, aiming at reducing the hardness and facilitating pre-machining. The furnace used in the heat treatment is a crucible type furnace and the annealing temperature was $700{ }^{\circ} \mathrm{C}$ for 6 hours. The cooling took place inside the furnace itself until it reached a temperature close to the room temperature.

The pre-machining was carried out in a conventional lathe, using carbide tools for allowance removal. For quenching, the temperature was raised to $1050{ }^{\circ} \mathrm{C}$ and maintained for 2 hours, and the cooling was done by forced ventilation, a procedure suggested by Tabrett and Sare17. After cooling down, the samples were taken back to the furnace and underwent tempering, remaining at $200{ }^{\circ} \mathrm{C}$ for 2 hours and then cooled in air.

The chemical analysis of the alloys was based on optical emission spectrometry (OES) using a SPECTROMAXx spectrometer. The alloys were characterised in the as-cast state, and after annealing, quenching, and tempering. The phases were identified using a Philips-PANalytical PW 1710 X-ray diffractometer equipped with $\mathrm{Cu} \operatorname{Ko} \alpha$ radiation $(\lambda=1,54056 \AA)$, in a range of 30 to $100^{\circ}(2 \theta)$, with a step of $0.02^{\circ}$ per second, $50 \mathrm{kV}$ of voltage and $35 \mathrm{~mA}$ of current. The microstructure was analysed by scanning electron microscopy (SEM), a using a JEOL JSM-6510 LV microscope equipped with a Thermo Fisher Scientific NSS 2.3 Energy Dispersion Spectrometer (EDS). The Rockwell hardness (HRC) was measured using a Dura Visio DV30 universal durometer.

A Fiji Is Just Image J software was utilised to determine the CVF. The samples were polished and chemically etched with Vilella. Then, SEM images with $500 \times$ magnification were obtained, resulting in total of 20 images for each treatment condition.

The machine tool used in the experiments was a horizontal lathe with Computer Numerical Control (CNC),

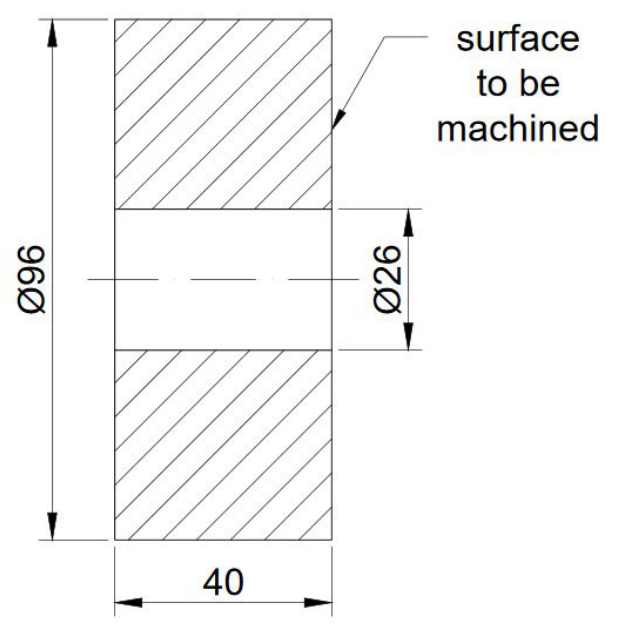

Figure 1. Work piece.

Table 1. Chemical composition of molten alloys, weight basis (\%).

\begin{tabular}{|c|c|c|c|c|c|c|c|c|c|c|}
\hline Alloy & Class & Type & $\mathrm{C}$ & $\mathrm{Mn}$ & $\mathrm{Si}$ & $\mathrm{Ni}$ & $\mathrm{Cr}$ & Mo & $\mathrm{Cu}$ & $\mathrm{Nb}$ \\
\hline $\begin{array}{c}\text { ASTM } \\
\text { A532 }\end{array}$ & III & A & $2.0-3.3$ & $2.0 \max$ & $1.5 \max$ & $2.5 \max$ & $23.0-30.0$ & $3.0 \max$ & $1.2 \max$ & - \\
\hline $\mathrm{A}$ & \multicolumn{2}{|c|}{$0 \% \mathrm{Nb}$} & 3.222 & 0.942 & 1.230 & 0.464 & 25.594 & 0.090 & 0.136 & 0.117 \\
\hline $\mathrm{B}$ & \multicolumn{2}{|c|}{$0.5 \% \mathrm{Nb}$} & 3.092 & 0.931 & 1.217 & 0.467 & 25.313 & 0.089 & 0.138 & 0.610 \\
\hline
\end{tabular}


IT 600 model, $40.3 \mathrm{~kW}$ power, 4000 RPM maximum rotation and hydraulic clamping. The experiments were performed with a pcBN tool meeting the SNGA120408 specifications, class CB7025, uncoated, with $60 \% \mathrm{cBN}$ and bimodal grain distribution (1 and $3 \mu \mathrm{m})$. The tool holder used was the DSSNR 2020K 12 leading to the following main angles: main position angle $(\chi r): 45^{\circ}$, secondary position angle $\left(\chi r^{\prime}\right): 45^{\circ}$, exit angle $(\gamma 0):-6^{\circ}$, and slope angle $(\gamma s):-6^{\circ}$.

The nuts were modified to increase the contact surface and improve sample fastening and positioning. The cutting parameters used were the same for both alloys: $0.20 \mathrm{~mm}$ cutting depth, $0.12 \mathrm{~mm} / \mathrm{rev}$ feed, and 100, 150 and $200 \mathrm{~m} /$ min cutting speed. Three tests were performed for each analysed condition. The machining times were simulated using the MasterCam software.

The maximum flank wear $\left(\mathrm{VB}_{\mathrm{Bmax}}\right)$ and roughness were measured with 2 or 4 passes interval, depending on their evolution. The roughness was determined using the SJ310 model portable roughness meter with $0.8 \mathrm{~mm}$ sampling length. The surface parameters analysed were mean arithmetic deviation $(\mathrm{Ra})$ and profile total height $(\mathrm{Rt}) ; 8$ measurements were made on the newly machined surface of each sample, spaced at $45^{\circ}$. The tests were interrupted when the cutting tool reached maximum flank wear or 30-minute machining time. The evaluation of the wear mechanisms was completed by SEM.

For data analysis and statistical treatment, we used the bicaudal $t$ test when comparing only two populations and the ANOVA (Analysis of variance) method - single factor for comparison of more than two populations.

\section{Results and Discussion}

\subsection{Hardness}

Figure 2 shows HCCI hardness as a function of niobium content and heat treatment.

The t-test of the samples was used to evaluate if there is a statistical difference in hardness between the alloys, using a 5\% significance level as shown in Table 2 . For $\mathrm{p}<0.05$ values, it is possible to affirm that the mean hardness values are different. Statistically, the heat treatment changed all alloys hardness,

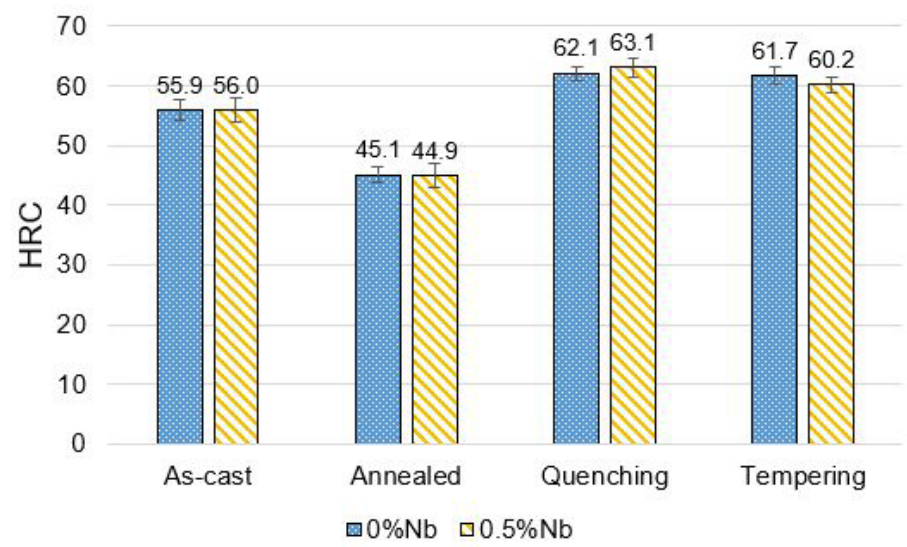

Figure 2. Hardness of alloys, with and without niobium.

Table 2. Hardness t-test of alloys, as a function of heat treatment.

\begin{tabular}{ccccccccc}
\hline \multicolumn{1}{c}{ p-value for condition } \\
\hline $\begin{array}{c}\text { Sample } \\
\text { condition }\end{array}$ & $\begin{array}{c}\text { As-cast } 0 \% \\
\mathrm{Nb}\end{array}$ & $\begin{array}{c}\text { Annealed } \\
0 \% \mathrm{Nb}\end{array}$ & $\begin{array}{c}\text { Quenching } \\
0 \% \mathrm{Nb}\end{array}$ & $\begin{array}{c}\text { Tempering } \\
0 \% \mathrm{Nb}\end{array}$ & $\begin{array}{c}\text { As-cast } 0.5 \% \\
\mathrm{Nb}\end{array}$ & $\begin{array}{c}\text { Annealed } \\
0.5 \% \mathrm{Nb}\end{array}$ & $\begin{array}{c}\text { Quenching } \\
0.5 \% \mathrm{Nb}\end{array}$ & $\begin{array}{c}\text { Tempering } \\
0.5 \% \mathrm{Nb}\end{array}$ \\
\hline $\begin{array}{c}\text { As-cast } 0 \% \\
\mathrm{Nb}\end{array}$ & - & $8.20 \mathrm{E}-14$ & $4.37 \mathrm{E}-09$ & $7.89 \mathrm{E}-09$ & 0.86 & $5.50 \mathrm{E}-13$ & $3.26 \mathrm{E}-10$ & $1.68 \mathrm{E}-06$ \\
\hline $\begin{array}{c}\text { Annealed } \\
0 \% \mathrm{Nb}\end{array}$ & $8.20 \mathrm{E}-14$ & - & $1.11 \mathrm{E}-18$ & $3.12 \mathrm{E}-18$ & $1.97 \mathrm{E}-14$ & 0.71 & $2.17 \mathrm{E}-17$ & $6.57 \mathrm{E}-17$ \\
\hline $\begin{array}{c}\text { Quenching } \\
0 \% \mathrm{Nb}\end{array}$ & $4.37 \mathrm{E}-09$ & $1.11 \mathrm{E}-18$ & - & 0.10 & $2.31 \mathrm{E}-09$ & $9.95 \mathrm{E}-16$ & 0.07 & $3.47 \mathrm{E}-05$ \\
\hline $\begin{array}{c}\text { Tempering } \\
0 \% \mathrm{Nb}\end{array}$ & $7.89 \mathrm{E}-09$ & $3.12 \mathrm{E}-18$ & 0.10 & - & $3.18 \mathrm{E}-09$ & $2.54 \mathrm{E}-16$ & $1.99 \mathrm{E}-02$ & $4.28 \mathrm{E}-03$ \\
\hline $\begin{array}{c}\text { As-cast } 0.5 \% \\
\mathrm{Nb}\end{array}$ & 0.86 & $1.97 \mathrm{E}-14$ & $2.31 \mathrm{E}-09$ & $3.18 \mathrm{E}-09$ & - & $1.73 \mathrm{E}-12$ & $5.99 \mathrm{E}-09$ & $4.75 \mathrm{E}-07$ \\
\hline $\begin{array}{c}\mathrm{Annealed} \\
0.5 \% \mathrm{Nb}\end{array}$ & $5.50 \mathrm{E}-13$ & 0.71 & $9.95 \mathrm{E}-16$ & $2.54 \mathrm{E}-16$ & $1.73 \mathrm{E}-12$ & - & $4.33 \mathrm{E}-17$ & $1.11 \mathrm{E}-14$ \\
\hline $\begin{array}{c}\text { Quenching } \\
0.5 \% \mathrm{Nb}\end{array}$ & $3.26 \mathrm{E}-10$ & $2.17 \mathrm{E}-17$ & 0.07 & $1.99 \mathrm{E}-02$ & $5.99 \mathrm{E}-09$ & $4.33 \mathrm{E}-17$ & - & $1.21 \mathrm{E}-05$ \\
\hline $\begin{array}{c}\text { Tempering } \\
0.5 \% \mathrm{Nb}\end{array}$ & $1.68 \mathrm{E}-06$ & $6.57 \mathrm{E}-17$ & $3.47 \mathrm{E}-05$ & $4.28 \mathrm{E}-03$ & $4.75 \mathrm{E}-07$ & $1.11 \mathrm{E}-14$ & $1.21 \mathrm{E}-05$ & - \\
\hline
\end{tabular}


except between quenching and tempering with no niobium addition alloy, where tempering did not change hardness. The niobium addition caused hardness statistical difference in the same heat treatment, only in the tempered condition.

The alloy without added niobium was approximately $2.4 \%$ harder than the alloy with added niobium. According to Maja et al. ${ }^{18}$, the reduction in hardness due to the addition of niobium can be justified by the reduced volumetric fraction of $\mathrm{M}_{7} \mathrm{C}_{3}$ carbides.

The material hardness obtained after annealing of nearly $45 \mathrm{HRC}$, converges with Amorim et al. ${ }^{7}$; however, the authors annealed the material at $710{ }^{\circ} \mathrm{C}$ for 12 hours. The annealing treatment is important to facilitate the rough machining of the material. This hardness represents a drop of approximately $20 \%$ in relation to the hardness of the material in its as-cast state and approximately $26 \%$ below that of the quenched and tempered material. The hardness was monitored during testing as the material was removed, and remained constant, evidencing the homogeneity of hardness across the roughened depth.

\subsection{Microstructure analysis}

The microstructural analysis was performed after each heat treatment step to observe variations in the microstructure at each treatment cycle. The details of each phase are described below.

\subsubsection{As-cast}

Hypereutectic HCCI alloys solidified into basically $\mathrm{M}_{7} \mathrm{C}_{3}$ type primary carbides and austenitic matrix similar to the results of Chung et al. ${ }^{19}$. The micrographs shown in Figure 3 disclose the microstructure of the material in the as-cast condition for both the material with addition and the material without addition of niobium. It is possible to note a predominantly austenitic matrix with some perlite colonies in both cases; perlite formation may have been facilitated by the low cooling speed of the material and/or high silicon content in the alloy. Amorim et al. ${ }^{7}$ point out that Si contents above $1 \%$ may increase perlite formation and compromise the temperability of the alloy. The casting cluster had a total weight of $\sim 24 \mathrm{~kg}$, and the low cooling speed may have increased the diffusion, facilitating perlite formation in the alloy. It is also possible to notice the occurrence of primary carbides in both alloys, indicating the alloys are hypereutectic. Moreover, the addition of $0.5 \% \mathrm{Nb}$ was not enough to displace the alloy from the hypereutectic to the eutectic condition. The presence of compact niobium carbides $(\mathrm{NbC})$ can be observed in Figure $3 \mathrm{~b}$; these compact carbides were also found by Ibrahim et al. ${ }^{20}$ and Filipovic et al. ${ }^{21,22}$ for niobium additions above $1.5 \%$. These carbides appeared in the alloy in two forms, integrated with chromium carbides $\mathrm{M}_{7} \mathrm{C}_{3}$ or isolated on the matrix. Such integration suggests that $\mathrm{NbC}$ carbides may have acted as nucleators of $\mathrm{M}_{7} \mathrm{C}_{3}$ primary carbides similarly to the nucleation of austenite dendrites reported by Filipovic et al. ${ }^{21}$ and Ibrahim et al. ${ }^{20}$.

In the chemical mapping of Figure 4, the predominance of iron in the matrix is visible, as well as the predominance of chromium in $\mathrm{M}_{7} \mathrm{C}_{3}$ carbides. It can be noted that the perlite

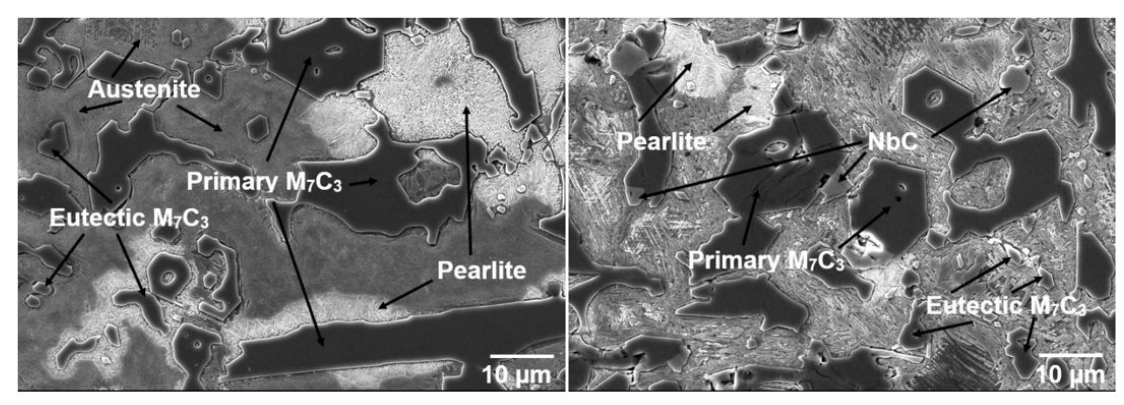

(a) $0 \% \mathrm{Nb}$

(b) $0.5 \% \mathrm{Nb}$

Figure 3. Samples of untreated alloys.

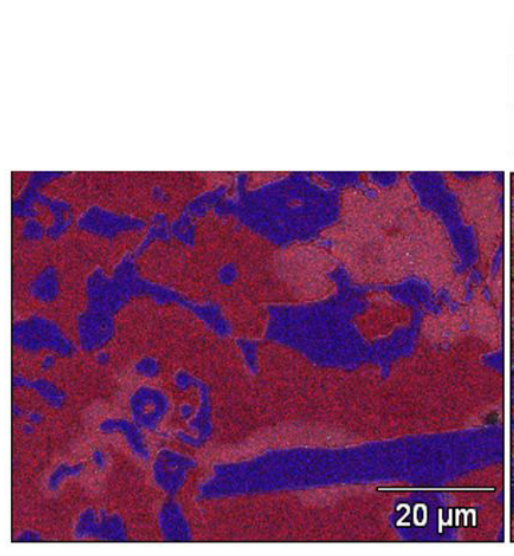

(a) $0 \% \mathrm{Nb}$
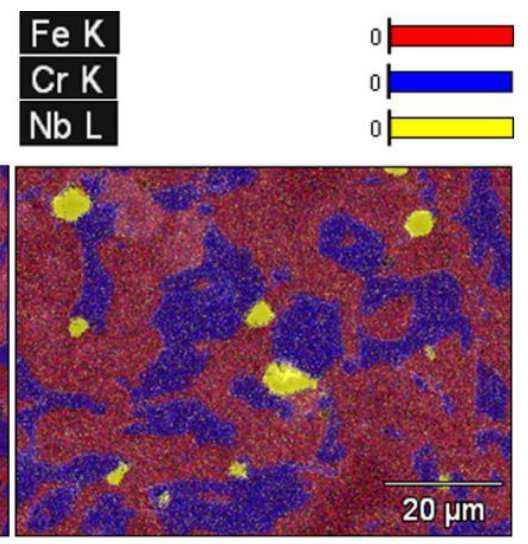

(b) $0.5 \% \mathrm{Nb}$

Figure 4. Chemical mapping of untreated alloys. 
region was lighter in colour. Although the alloy without niobium shows a residual $0.117 \% \mathrm{Nb}$ content, this was not enough to generate carbides and was $\mathrm{Nb}$ not identified in the chemical mapping of the alloy as shown in Figure $4 \mathrm{a}$.

The mapping of the niobium containing alloy in Figure $4 \mathrm{~b}$ shows that all niobium carbides are in the compact form. Ibrahim et al. ${ }^{20}$ worked with hypoeutectic alloys and found compact carbides only in the alloy containing $2.14 \% \mathrm{Nb}$; all carbides identified by the authors, in the alloy containing $1.35 \% \mathrm{Nb}$, were in the form of needles. Most niobium carbides are integrated with chromium carbides, but it is possible to identify some carbides that were formed separately on the matrix, indicating that $\mathrm{NbC}$ carbides may have acted as nucleators of the primary carbides and also of the eutectic as suggested by Filipovic et al. ${ }^{21}$. Possibly, in the niobium added alloy, due to the carbon consumption in niobium carbide formation and decrease in the volumetric fraction of $\mathrm{M}_{7} \mathrm{C}_{3}$ type carbides, the matrix has a higher chromium content, reducing the occurrence of perlite; similar behaviour was observed by Filipovic et al. ${ }^{22}$.

\subsubsection{Annealing}

Annealing had the purpose of decreasing hardness and obtaining the highest possible amount of ferrite in the structure of the material, due to the need of machining the parts before the quenching process, a similar procedure to what was adopted by Ortega-Cubillos et al. ${ }^{23}$. Figure 5 displays the conversion of the initial predominantly austenitic matrix, containing a few perlite colonies, into an unstable matrix, transformed with high content of secondary carbides, possibly involved by ferrite, in both alloys.

The chemical mapping carried out after the HCCI annealing treatment is shown in Figure 6.

Figure 6 shows that the matrix of the material was homogenised with all austenite and perlite initially unstable. The matrix formed basically by ferrite and precipitated secondary carbides has lower hardness than the austenitic matrix, which improves machinability, thus allowing the thinning of samples before the quenching treatment. Annealing has not caused any changes in the morphology of the primary and eutectic chromium carbides or niobium carbides.

\subsubsection{Quenching and tempering}

The quenching treatment seeks to modify the material matrix, transforming it into a martensitic matrix of high hardness, with the possibility of precipitated secondary carbides. The secondary carbides can favour the wear resistance of HCCI, and they form during the heat treatment. Thus, it is possible to increase the hardness of the material and, possibly, its wear resistance ${ }^{3,24}$. Figure 7 a shows primary and eutectic $\mathrm{M}_{7} \mathrm{C}_{3}$ carbides surrounded by a matrix composed predominantly of martensite and secondary carbides. A similar

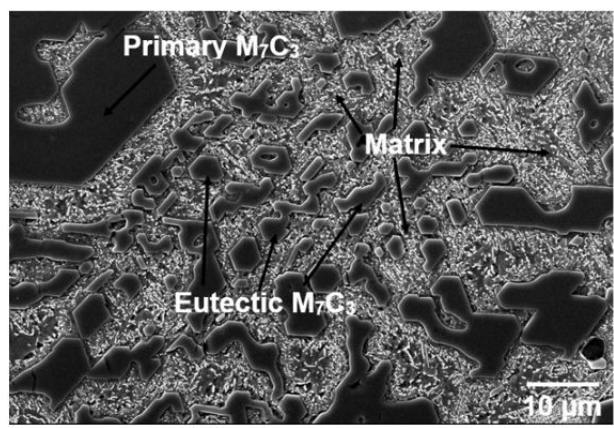

(a) $0 \% \mathrm{Nb}$

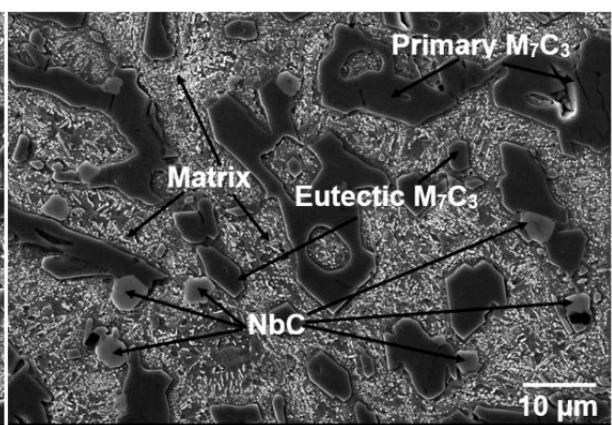

(b) $0.5 \% \mathrm{Nb}$

Figure 5. Samples of alloys after annealing.

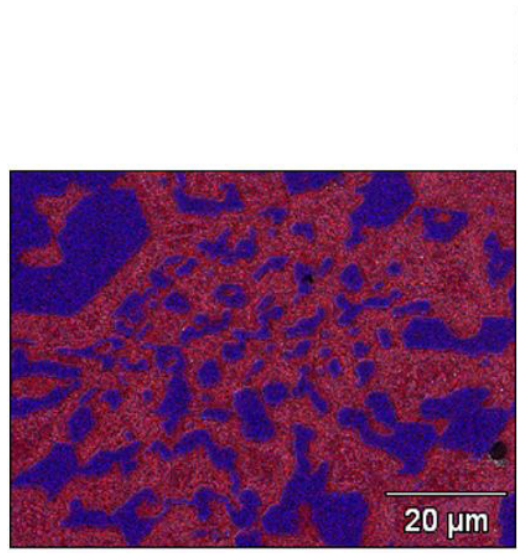

(a) $0 \% \mathrm{Nb}$
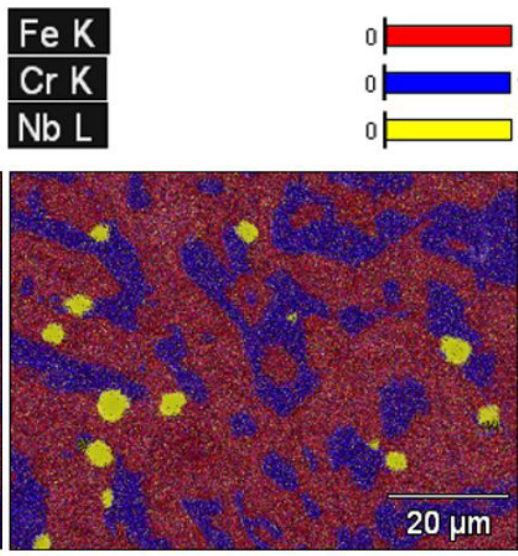

(b) $0.5 \% \mathrm{Nb}$

Figure 6. Chemical mapping of annealed alloys. 


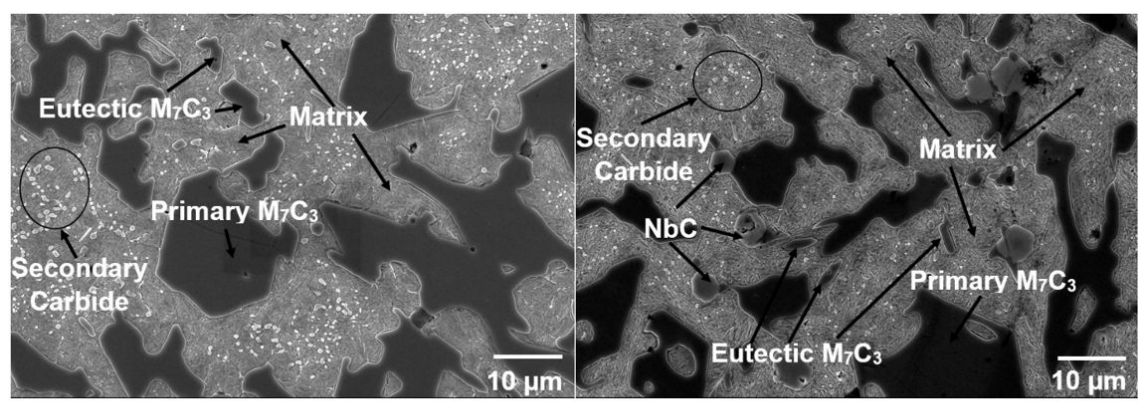

(a) $0 \% \mathrm{Nb}$

(b) $0.5 \% \mathrm{Nb}$

Figure 7. Samples of quenched alloys.

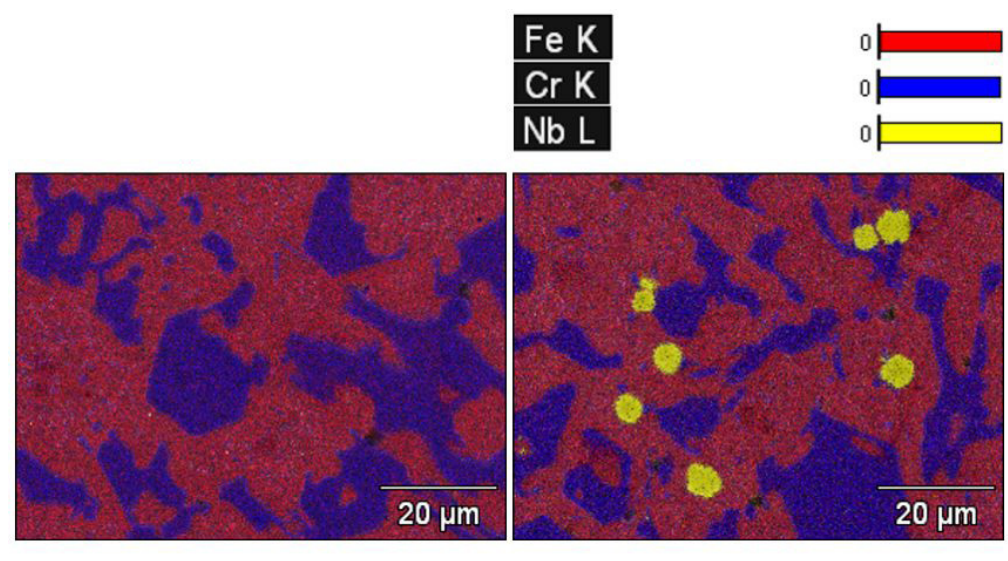

(a) $0 \% \mathrm{Nb}$

(b) $0.5 \% \mathrm{Nb}$

Figure 8. Chemical mapping of alloys after quenching.

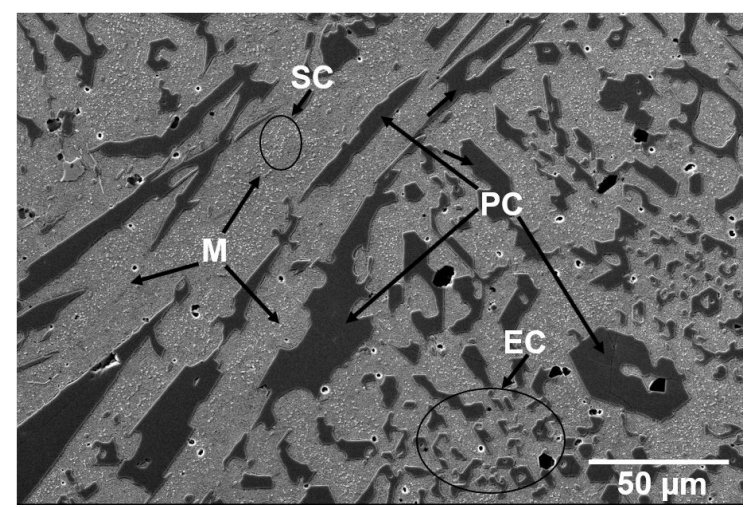

Figure 9. Alloy with no added niobium after quenching and tempering.

microstructure can be observed in Figure 7b, differentiated by the presence of $\mathrm{NbC}$ compact carbides. Obtaining the predominantly martensitic matrix can optimise the performance of the alloy in terms of wear resistance according to Powell and Laird ${ }^{24}$ and Tabrett et al. ${ }^{3}$.

Figure 8 illustrates the chemical mapping of the alloys after quenching. It can be noted that the secondary carbides are rich in chromium, as well as the primary and eutectic carbides. The formation of secondary carbides can also contribute to the increased hardness of the alloy as a whole and aid in its wear resistance ${ }^{24}$.

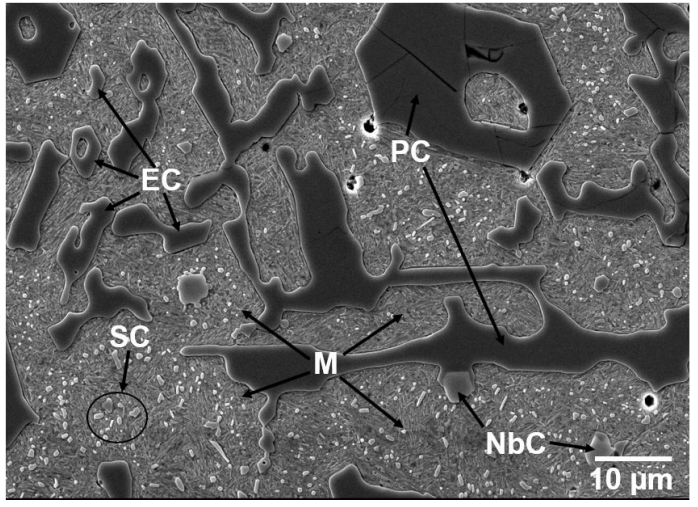

Figure 10. Alloy with addition of niobium after quenching and tempering.

Tempering does not cause major changes to the microstructure of the material, since the treatment temperatures are very low, but it is important for relieving internal stresses caused by quenching ${ }^{23}$. The samples in this work were machined in the tempered condition, so the microstructures shown below represent the microstructures of the machined surfaces. Figures 9 and 10 show the microstructure of the alloys after quenching and tempering. The matrix is martensitic, with the presence of small secondary carbides. The primary chromium carbides, the eutectic carbides and the niobium carbides have not undergone morphological changes due to 
the heat treatment. The morphology of the microstructure is presented in the figures, highlighting the martensitic matrix (M), the secondary carbides (SC), the primary carbides (PC), the eutectic carbides $(\mathrm{EC})$ and the niobium carbides $(\mathrm{NbC})$.

The presence of niobium carbides dispersed in the matrix and in border regions with chromium carbides can be seen in Figure 10.

Figure 11 shows the presence of the predominantly martensitic matrix, and the chromium secondary carbides, possibly also of $\mathrm{M}_{7} \mathrm{C}_{3}$ type as suggested by Powell and Laird ${ }^{24}$. However, these carbides were formed as a function of the heat treatment, due to the transformation of the austenitic matrix into a martensitic matrix.

Figure 12 shows a niobium carbide interconnected with chromium carbide; these carbides were formed during solidification, and possibly, the niobium carbides acted in the alloy as a nucleating agent for the chromium carbides. In addition, a contact interface between $\mathrm{M}_{7} \mathrm{C}_{3}$ and $\mathrm{NbC}$ carbides formed in the solidification can be observed.

\subsection{Microstructure analysis - X-Ray Diffraction (XRD)}

Figure 13 shows the XRD results of HCCI alloys with and without addition of niobium, in as-cast conditions, and after annealing, quenching and tempering. Four phases were

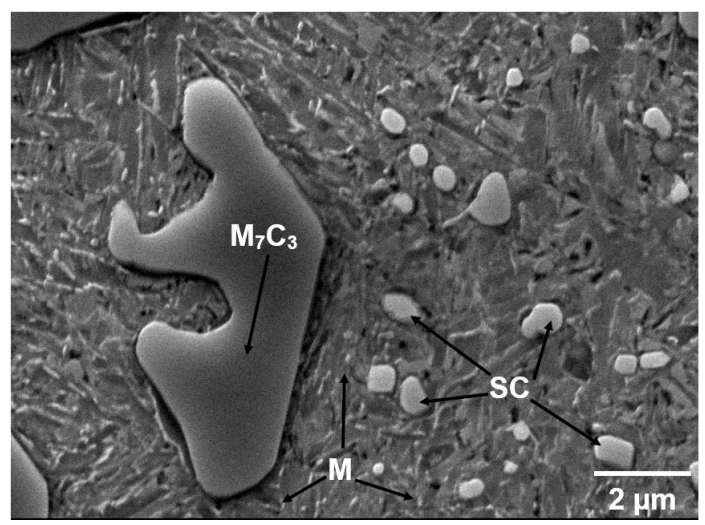

Figure 11. Secondary carbides in the alloy with no niobium addition, after quenching and tempering.

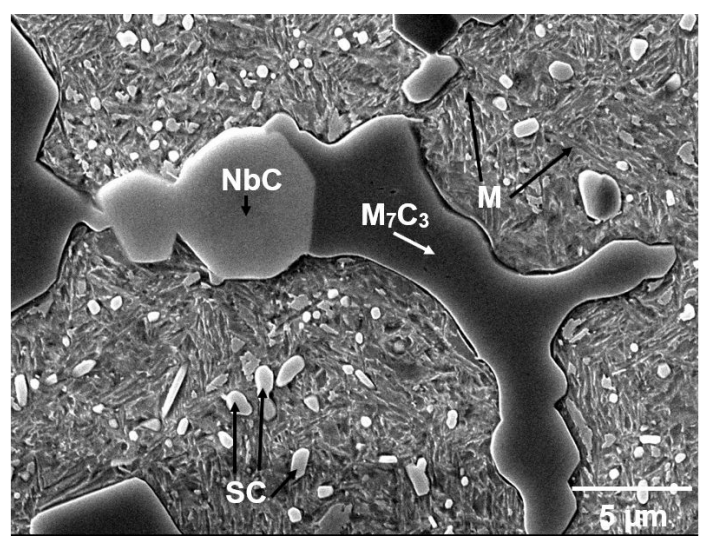

Figure 12. Niobium carbides and secondary carbides in the niobium added alloy after quenching and tempering. highlighted in the analysis: austenite $(\gamma), \mathrm{M}_{7} \mathrm{C}_{3}$ chromium carbides $(\mathrm{C})$, niobium carbides $(\mathrm{N})$ and martensite/ferrite (M), where the peaks may correspond to both ferrite and martensite, since the peaks of these two phases are coincident.

Niobium carbide was identified at the $35^{\circ}$ angle position in the alloys with addition of niobium, both in the as-cast and heat-treated alloys. This indicates that the addition of niobium formed $\mathrm{NbC}$ carbides which are not affected by heat treatment. This peak was also identified previously by Chung et al. ${ }^{19}$.

$\mathrm{M}_{7} \mathrm{C}_{3}$ chromium carbides were identified in all heat treatment phases and in all the analysed samples. The peaks for $\mathrm{M}_{7} \mathrm{C}_{3}$ can be identified at $39,43,44.5,51$ and $82.5^{\circ}$, and these peaks were found in a similar way by other authors, such as Higuera-Cobos et al. ${ }^{25}$ and Ibrahim et al. ${ }^{20}$. The peaks visible at 44.5 and $82.5^{\circ}$ indicate a peak coincidence between chromium carbide and ferrite/martensite, as well as the peak at $51^{\circ}$ indicates an overlap of austenite and chromium carbide peaks. This overlap was similarly identified by Higuera-Cobos et al. ${ }^{25}$.

The intensities of the chromium carbide peaks identified at the angles 39 and $43^{\circ}$ in both alloys increased after the annealing, when compared to those of as-cast samples. Primary and eutectic carbides were not modified due to the heat treatment; however, this increase can be explained by the precipitation of secondary carbides, originating from austenite destabilisation during annealing, on the matrix ${ }^{23}$.

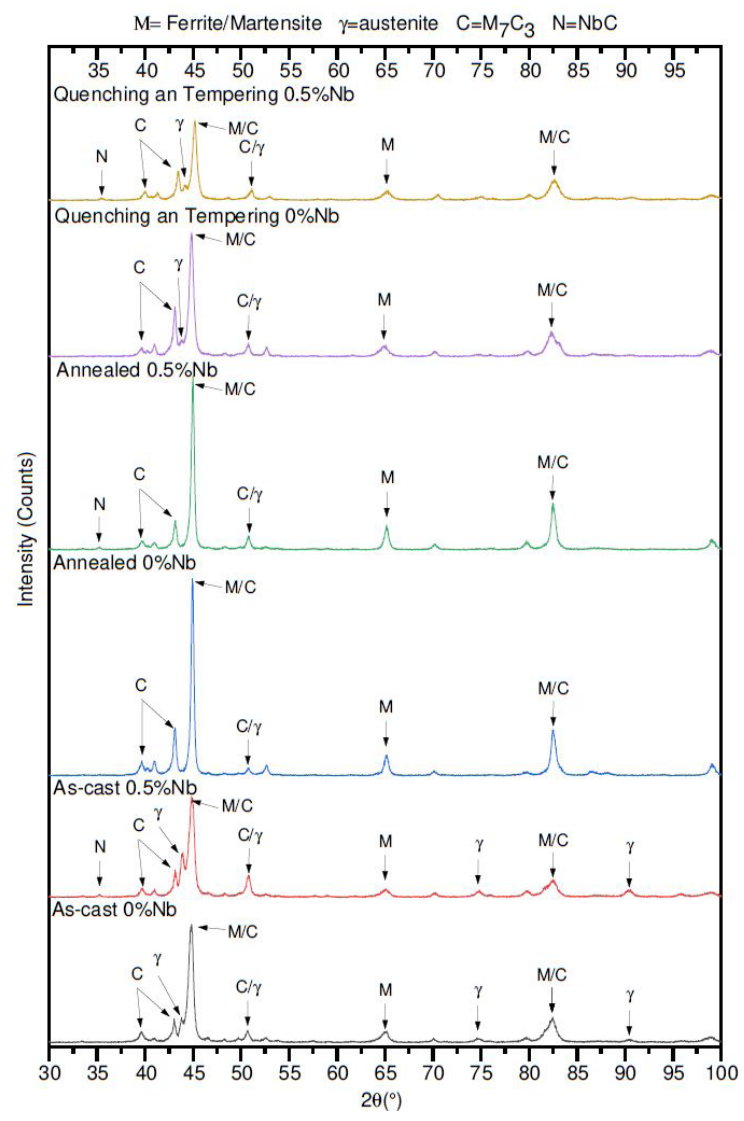

Figure 13. X-ray diffraction results for HCCI alloys with and without addition of niobium. 
The peaks with chromium carbide and ferrite/martensite overlapping, identified at 44.5 and $82.5^{\circ}$, showed maximum intensity in the annealed condition, for both alloys. This fact may be associated with the missing austenite peaks identified at $43.5,74.5$ and $91^{\circ}$ in this phase of the heat treatment. Possibly, all the austenite, or a large part of it, was destabilised and converted into secondary chromium carbides and ferrite, indicating that the heat treatment was efficient, and that the destabilisation time was appropriate for transforming the austenite as indicated.

With quenching and tempering heat treatments, the ferrite/martensite peak at $65^{\circ}$, showed a slight decrease when compared to the $\mathrm{M}_{7} \mathrm{C}_{3}$ chromium carbide peaks, as well as to the 44.5 and $82.5^{\circ}$ peaks of ferrite/martensite, compared to the annealed alloys. This indicates that the angles with overlapping ferrite/martensite and $\mathrm{M}_{7} \mathrm{C}_{3}$ suffered greater oscillation due to the $\mathrm{M}_{7} \mathrm{C}_{3}$ carbides. Possibly, the matrix formed basically of ferrite and secondary carbides in the annealing underwent a new transformation losing part of these secondary carbides, enriching the matrix with carbon, to allow the emergence of the new matrix, formed basically of martensite, retained austenite and secondary carbides.

Austenite, in both as-cast alloys, can be identified by the occurrence of peaks at 43.5, 74.5 and $91^{\circ}$. After annealing, these peaks disappear as mentioned above, indicating the complete dissolution of austenite. Upon quenching and tempering, the peak at $43.5^{\circ}$ reappears in both alloys, but with lower intensity than previously observed in the as-cast condition, evidencing the presence of retained austenite in the alloy.

It can be concluded that the addition of niobium formed NbC-type niobium carbides in the corresponding alloys, and that these carbides are not influenced by heat treatment. Alloys without heat treatment are formed basically by austenitic matrices, with primary and eutectic $\mathrm{M}_{7} \mathrm{C}_{3}$ carbides, and may contain small quantities of martensite/ferrite. With the annealing treatment, the microstructure is formed by primary and eutectic $\mathrm{M}_{7} \mathrm{C}_{3}$ carbides, and the austenite is destabilised and forms a ferritic matrix with precipitated carbides. After quenching and tempering, the final microstructure is formed by primary and eutectic $\mathrm{M}_{7} \mathrm{C}_{3}$ chromium carbides, with a predominantly martensitic matrix with precipitated secondary carbides, still containing retained austenite.

\subsection{Carbide Volume Fraction - CVF}

The volumetric fraction of carbides in the alloys with and without addition of niobium are shown in Table 3.

Table 4 shows the t-test used to evaluate the occurrence of statistical difference in the CVF between alloys, using a $5 \%$ significance level. It is possible to affirm that the values are statistically different.

The lower CVF in the niobium containing alloy was already expected due to the formation of niobium carbides. Part of the carbon in the alloy is destined to the formation of niobium carbides, impoverishing the bath, and reducing the formation of chromium carbides, also favouring a possible refinement in hypereutectic alloys ${ }^{18}$. The refinement of the alloy and the reduction in size of primary and eutectic carbides was also identified by Zhi et al. ${ }^{26}$ when niobium was added to HCCI. The carbide content and distribution in
Table 3. Carbide Volume Fraction.

\begin{tabular}{ccc}
\hline \multicolumn{3}{c}{ Carbides Volume Fraction } \\
\hline Alloy & CVF & Standard Deviation \\
\hline $0 \% \mathrm{Nb}$ & 27.30 & 3.03 \\
\hline $0.5 \% \mathrm{Nb}$ & 24.83 & 3.09 \\
\hline
\end{tabular}

Table 4. t-test of CVF

\begin{tabular}{cccc}
\hline Analysis & p-value & $\alpha$ & Conclusion \\
\hline CVF & 0.00617 & 0.05 & Different \\
\hline
\end{tabular}

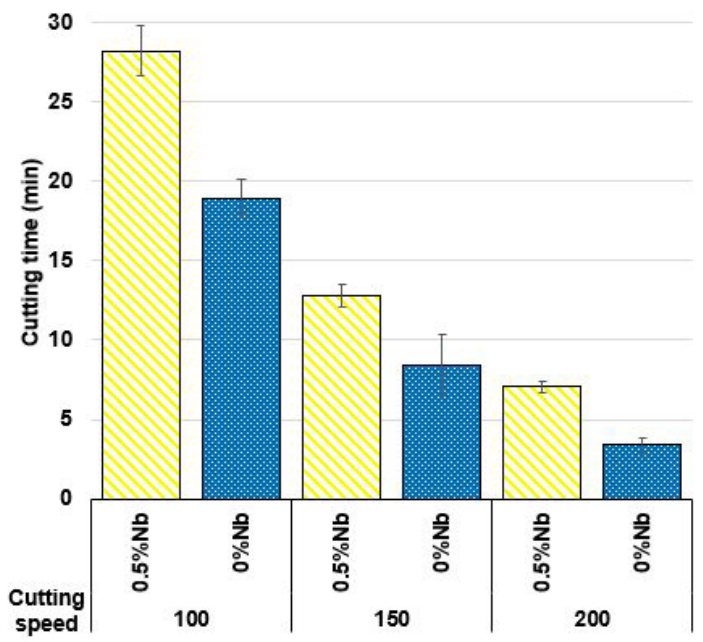

Figure 14. Cutting tools service life.

the alloy plays an important role in the wear resistance of the material, and more homogeneous distributions improve its performance when subjected to wear ${ }^{27}$. Furthermore, it is possible that the refinement of the alloy is beneficial to increase its machinability, since it increases the microstructural homogeneity and reduces the impact of large carbides with the cutting tool, improving the material's machinability.

\subsection{Tool service life}

One of the major considerations to be made in hard turning is the quality of the parts, since flank wear has a high impact on surface finish, geometric accuracy, and surface integrity ${ }^{28}$. Parts with more stringent quality requirements may limit the cutting tool life to dimensional tolerances and surface finishing, reducing the feasibility of turning compared to the grinding process. Figure 14 shows the results of cutting tool life (in machining time) for HCCI turning, where the variables are material with and without addition of niobium and cutting speed.

Figure 15 highlights the progression of cutting tool wear as a function of the removed material volume.

The results on wear of cutting tools are presented and discussed separately according to cutting speed and niobium addition.

\subsubsection{Influence of cutting speed}

The increase in cutting speed strongly impacts on the cutting tool life, according to Laird et al. ${ }^{1}$. HCCI has high hardness carbides associated with a rigid matrix, which possibly hinders its machinability associated with increased 
heat generated as a result of increased cutting speed. This probably accelerated the wear mechanisms reducing cutting tool life, a behaviour also observed by Oliveira et al. ${ }^{6}$.

When increasing the cutting speed by $50 \%$ (from 100 to $150 \mathrm{~m} / \mathrm{min}$ ), the tool life decreased by approximately $50 \%$ in both alloys. At a cutting speed of $200 \mathrm{~m} / \mathrm{min}$, compared to $100 \mathrm{~m} / \mathrm{min}$, the decrease in tool life was approximately $75 \%$ in niobium- added material and $80 \%$ in non-added material.

A similar behaviour in flank wear can be observed, as a function of the increased cutting speed. In general, if the initial $100 \mathrm{~m} / \mathrm{min}$ cutting speed is analysed, an increase of $50 \%$ in this speed leads to a reduction in tool life of approximately half of its initial life. Once the cutting speed is twice as fast, the tool life is reduced to approximately one quarter of the life. This behaviour suggests that tool life in HCCI machining decreases with the increase of cutting speed, approximately linearly, under the analysed conditions; a similar behaviour was also found by Yallese et al. ${ }^{29}$ in hardened steel machining.

\subsubsection{Effect of niobium addition}

Studies made by Chen et al. ${ }^{30}$, Bouhamla et al. ${ }^{5}$ and Filipovic et al. ${ }^{21}$ point out that niobium insertions in HCCI may result in gains of wear resistance of these alloys, but very little is known about their influence on the alloy machinability. The tests results suggest that the addition of niobium considerably improves the machinability of the material. At 100 and $150 \mathrm{~m} /$ min speeds, the tool life gain compared to the material without niobium addition, was approximately $50 \%$. At $200 \mathrm{~m} / \mathrm{min}$ the tool life in the niobium added material was approximately $100 \%$.

The gain in tool life becomes even more evident in Figure 16, where it is possible to observe the coincident behaviour in the following cutting speeds: $200 \mathrm{~m} / \mathrm{min}$ with niobium addition and $150 \mathrm{~m} / \mathrm{min}$ without addition, and also $150 \mathrm{~m} / \mathrm{min}$ with niobium addition at $100 \mathrm{~m} / \mathrm{min}$ without addition. The niobium added material had an average hardness approximately $2.5 \%$ lower than the material with no niobium addition. This decrease is small to justify the tool life gains in such a proportion. HCCI has a complex and rigid microstructure, and its machinability cannot be analysed simply by the hardness. The carbides volume fraction reduction was approximately $9 \%$. As they are the hardest parts of the microstructure, the CVF reduction can significantly influence machinability. Zhi et al. ${ }^{26}$ identified that additions between $0.5 \%$ and $1.5 \%$ of niobium in hypereutectic alloys cause chromium carbides morphology changes, mainly in because of primary carbides size reduction, resulting in microstructure refinement. Similar behavior was also identified by Penagos et al. ${ }^{4}$. Silva et al. ${ }^{13}$ also observed an machinability increase with niobium addition using cutting fluid and cutting advances of $0.8 \mathrm{~mm} /$ rot.

Although the addition of niobium to the alloy is low, it is possible that small microstructural changes, such as a reduction in the carbide volume fraction and a probable refinement of the microstructure, have been essential to the increase in the service life of the cutting tools.

\subsection{Roughness analysis}

The wear of the cutting tool reflects directly on the roughness of the part and can even be used to determine the end of the tool life. The following analyses have taken

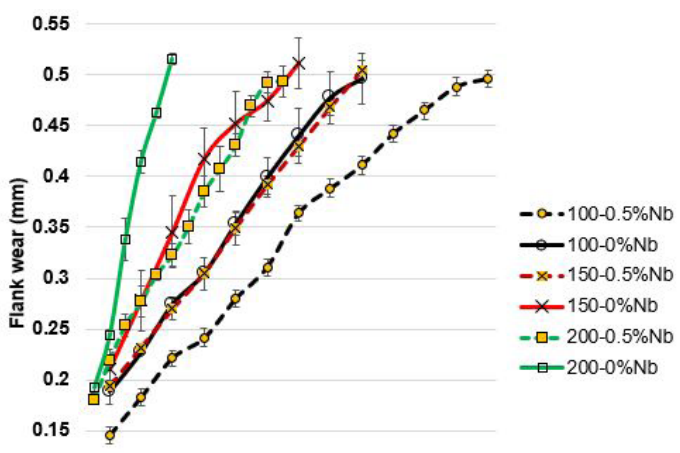

0.1

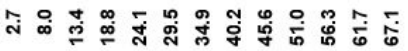

Material removed volume $\left(10^{3} \mathrm{~mm}^{3}\right)$

Figure 15. Evolution of flank wear.

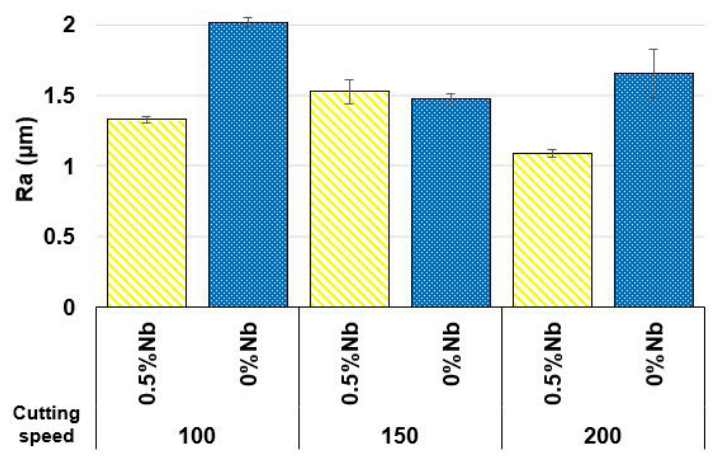

Figure 16. Mean arithmetic deviation - Ra.

into consideration the evolution of the roughness with the volume of removed material.

\subsubsection{Mean arithmetic deviation ( $R a)$}

Figure 16 shows the mean arithmetic deviation (Ra) at the end of the tests, for all analysed conditions.

Figure 16 shows that cutting speed, in general, did not correlate with the roughness. On average, niobium added alloys had lower roughness than alloys without niobium addition, and this phenomenon may be causally linked to the microstructure of the material, since the niobium added alloys were more refined. At a cutting speed of $150 \mathrm{~m} / \mathrm{min}$, the roughness of the alloy without addition of niobium was slightly lower than that of the niobium added alloy, contrary to the explanation above. By analysing the progression in roughness as a function of the volume of removed material in Figure 17, it can be seen that the alloy with no niobium showed higher values of roughness than the niobium added alloy in practically the entire test. However, there was a reversal of the trend as the tools approached the end of their service life. This may have occurred because the wear of the cutting tool momentarily caused a re-shaping of the cutting edge, creating a more uniform surface, and decreasing the momentary roughness in the alloy without the addition of niobium.

The evolution of roughness was increasing and practically linear, and showed results with similar trends, regardless of the cutting speed. It can be noted that roughness is causally 
linked to tool wear and suffers little influence from cutting speed. However, higher cutting speeds generally cause higher wear on tools, and thus the roughness increases more sharply over time, as roughness tends to increase with tool wear. Li et al. ${ }^{31}$ classified cutting tool wear as an important factor that directly affects the topography of the machined surface.

At a cutting speed of $200 \mathrm{~m} / \mathrm{min}$, in the niobium added alloy, a more atypical roughness behaviour can be observed, compared to the other tests. This behaviour may have been influenced by some microchipping on the cutting edge or some abnormal wear on the edge, changing its geometry and promoting the roughness decrease in the final tests. A similar behaviour was also found, at a cutting speed of $150 \mathrm{~m} / \mathrm{min}$ in the material with no niobium addition.

\subsubsection{Profile total height (Rt)}

Figure 18 displays the profile total height (Rt) obtained in all tests at the end of the useful life. In general, the behaviour evolution of the Rt roughness was remarkably similar the surface parameter Ra, increasing as the tool wear increases.

Although, in most tests, the niobium added material achieved less roughness than the material without addition of niobium, the difference was relatively small, indicating that the refinement of the alloy tends to have more effect on Ra than on Rt. In addition, no connection could be established between the roughness Rt and the cutting speed. Figure 19 shows the progress of Rt as a function of the volume of material removed, under all tested cutting speeds.

It is noticeable that the behaviour of Rt suffered more oscillations during the tests, indicating that under these conditions, Rt is more unstable than Ra. Probably, the geometry of the constantly changing cutting edge has more influence on Rt, since it causes additional microgrooves on the surface, which increases the values of Rt.

\subsection{Analysis of wear mechanisms}

The analysis of wear mechanisms is essential to interpret how tools wear during machining ${ }^{32}$. Although several wear mechanisms can act simultaneously on tool wear during machining, the analyses seek to identify the main wear mechanisms found in tools at the end of their life. Figure 20 shows the wear aspect on cutting tools at the end of their useful life.

Abrasion was the main wear mechanism shown in the tests, which is in accordance with Poulachon et al. ${ }^{28}$ who state that the main wear mechanism in pcBN tools is abrasion, caused mainly by carbide particles contained in the work piece alloy. Abrasion signs were mainly found on the tool flank, but it was also possible to find discrete grooves in the tool crater, indicating that abrasion may have also contributed to crater wear. The grooves were deeper and highlighted in the material with the addition of niobium. The alloys with niobium addition showed a more refined structure. This refinement indicates that the chromium carbides of the niobium added alloy are smaller than the chromium carbides of the non-niobium added alloy. Therefore, chromium carbides together with niobium carbides may have contributed to a higher number of grooves in the cutting tools, and these grooves were more visible and deeper in the niobium added alloy. The non-added niobium alloy, with larger chromium

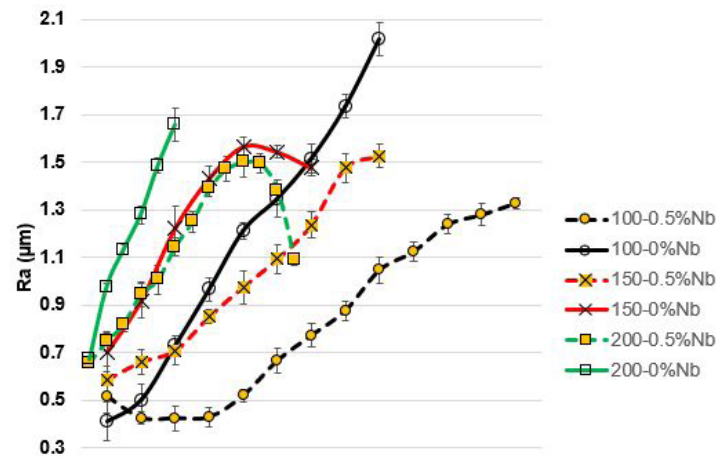

0.1

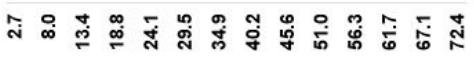

Material removed volume $\left(10^{3} \mathrm{~mm}^{3}\right)$

Figure 17. Mean arithmetic deviation (Ra) as a function of removed material volume.

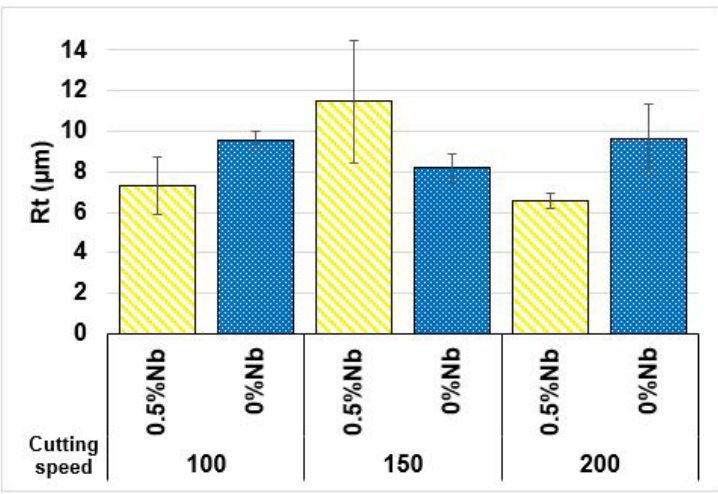

Figure 18. Profile total height (Rt).

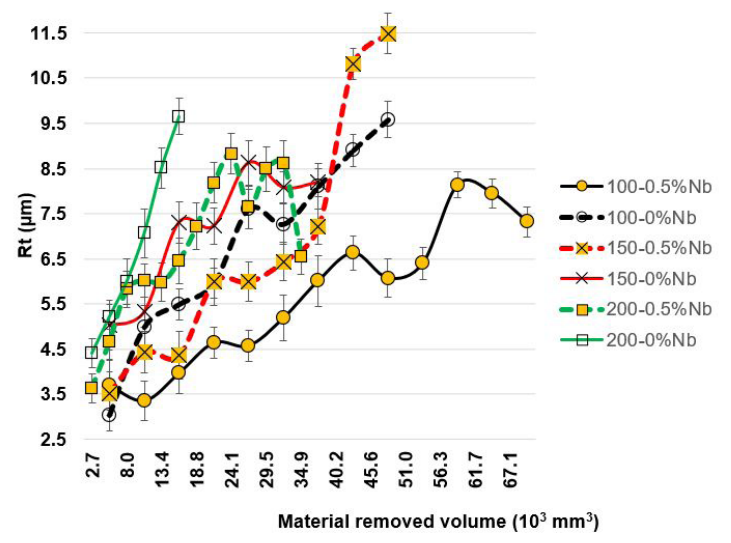

Figure 19. Profile total height (Rt) as a function of removed material volume.

carbides and the absence of niobium carbides, had more discrete grooves.

The crater wear was more pronounced in alloys with niobium addition; this phenomenon could be discretely noticed at $150 \mathrm{~m} / \mathrm{min}$ and more markedly at a cutting speed of $100 \mathrm{~m} / \mathrm{min}$. This wear can be associated with longer tool exposure to high temperatures, due to longer tool life when machining alloys with added niobium and a possible diffusion wear mechanism. The crater presented grooves 

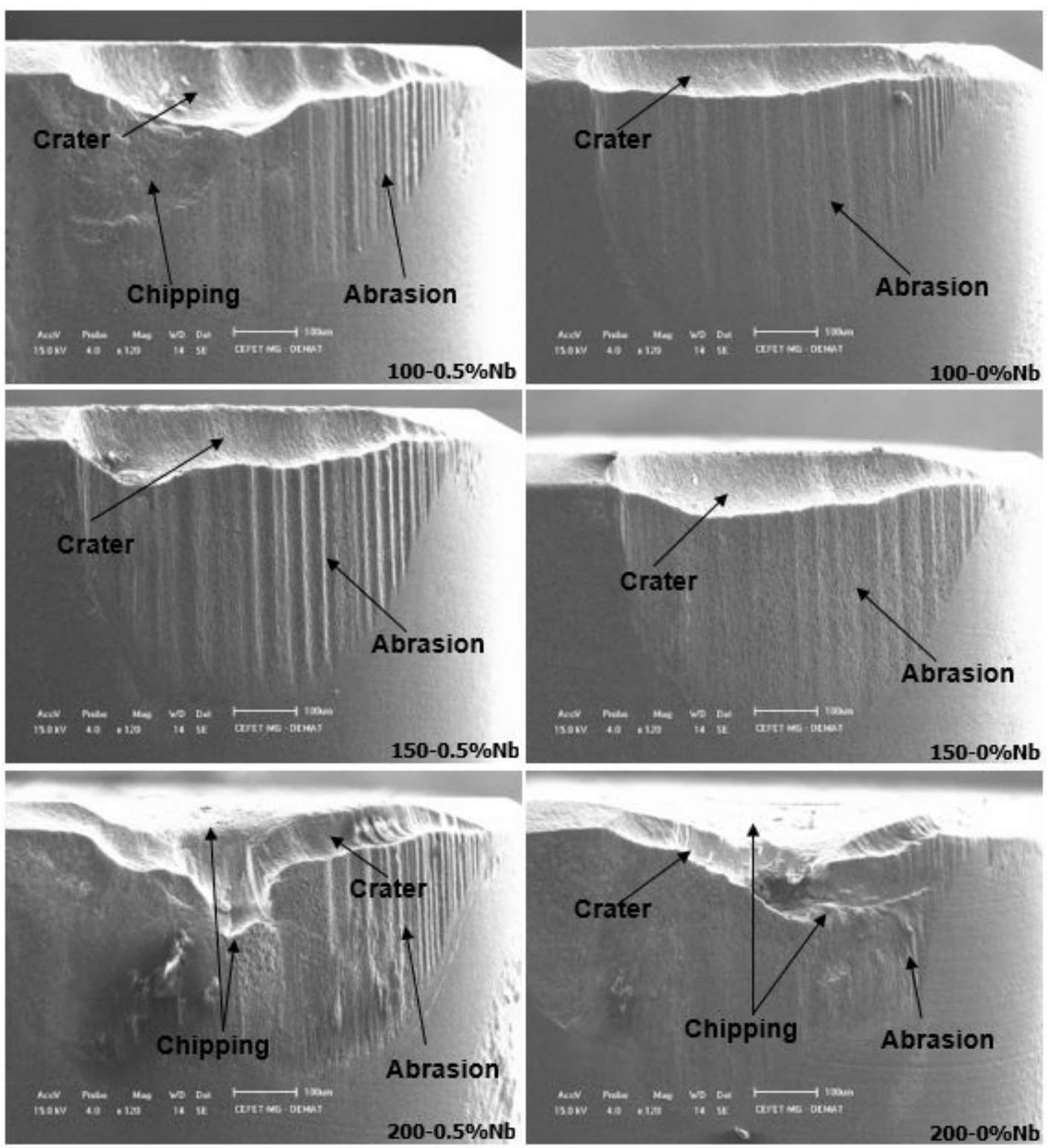

Figure 20. Wear appearance when machining HCCI with and without addition of niobium.

possibly produced by abrasion, but very discrete. Most of the crater had a relatively smooth surface, indicating that the diffusion phenomenon may have acted on the wear of this region at some point during machining, which would justify the increase of the crater due to the longer exposure time of the tool.

When machining material with niobium addition at $100 \mathrm{~m} / \mathrm{min}$, there was an edge chipping, noted by large cutting tool particles loss observation, which was probably motivated by the higher cutting force at lower cutting speeds. Ravi et al. ${ }^{33}$ identified that in HCCI turning, the cutting force decreases as the cutting speed increases, due to the hardness reduction of the working material. Silva et al. ${ }^{13}$ analyzed the machinability of the HCCI with 100, 200 and $300 \mathrm{~m} /$ min speeds and $0.8 \mathrm{~mm} / \mathrm{rev}$ feed, it is possible to observe in comparison to this study, that the feed increase little changed the friction wear, however, the cutting tools crater wear has considerably increased, potentiating edge chipping, especially at lower cutting speeds.

The increase in cutting speed may have considerably increased the machining temperatures, thus causing accelerated crater wear. As crater wear increases and associates with flank wear, the tool edge becomes brittle, and it is not able to withstand the machining forces generated in the process, chipping when the end of life approaches, especially at $200 \mathrm{~m} /$ min, in both materials. This edge fragility was also identified by Oliveira et al. ${ }^{6}$ in HCCI machining. Ren et al. ${ }^{34}$ identified edge chipping and flank wear as the main wear mechanisms in the machining of materials with high chromium content, identifying the load and abrasiveness of carbides as the main cause of wear. They also stated that increasing the cutting speed enhances such mechanisms. 


\section{Conclusion}

All formed niobium carbides were compact and dispersed in the alloy, and in most cases integrated with chromium carbides.

The carbide volume fraction fell from $27.3 \%$ to $24.83 \%$, but the alloy remained hypereutectic even after the $\mathrm{Nb}$ addition process.

The annealing treatment destabilised the austenite matrix, precipitating secondary carbides, impoverishing the austenite to the point of its total transformation into ferrite. The alloy hardness dropped by $19.8 \%$ after the treatment, improving its machinability. The quenching promoted the transformation of the matrix into martensitic, with precipitated secondary carbides and retained austenite.

The material hardness remained stable throughout the machined area after quenching and tempering, showing that the material has high hardenability.

The addition of niobium offers gains of approximately $50 \%$ in tool life at cutting speeds of 100 and $150 \mathrm{~m} / \mathrm{min}$, reaching approximately $100 \%$ at $200 \mathrm{~m} / \mathrm{min}$. Regarding roughness, in general, the alloys with niobium addition presented lower roughness than those with no niobium.

The predominant tool wear mechanism was abrasion. An increase in the number of grooves on the edges of the cutting tools was also observed, as well as a greater crater wear on alloys with the addition of niobium.

\section{Acknowledgment}

This work was carried out with the support of the Coordination for the Improvement of Higher Education Personnel - Brazil (CAPES), the Federal Centre for Technological Education of Minas Gerais (CEFET-MG) and SENAI Itaúna CETEF Marcelino Corradi.

\section{References}

1. Laird G, Gundlach R, Rohrig K. Abrasion-resistant cast iron handbook. Schaumburg, IL: American Foundry Society; 2000.

2. Gutnichenko O, Bushlya V, Zhou J, Ståhl J-E. Tool wear and machining dynamics when turning high chromium white cast iron with pcBN tools. Wear. 2017;390-391:253-69.

3. Tabrett CP, Sare IR, Ghomashchi MR. Microstructure-property relationships in high chromium white iron alloys. Int Mater Rev. 1996;41:59-82.

4. Penagos JJ, Pereira JI, Machado PC, Albertini E, Sinatora A. Synergetic effect of niobium and molybdenum on abrasion resistance of high chromium cast irons. Wear. 2017;376377:983-92.

5. Bouhamla K, Hadji A, Maouche H, Merradi H. Effet du niobium sur la resistance a l'usure d'une fonte au chrome traitee thermiquement. Rev Metall. 2011;108(2):83-8.

6. Oliveira AJ, Boing D, Schroeter RB. Effect of pcBN tool grade and cutting type on hard turning of high-chromium white cast iron. Int J Adv Manuf Technol. 2016;82:797-807.

7. Amorim P, Santos H, Santos J, Coimbra S, Sá C. Soft annealing of high chromium white cast iron. Mater Sci Forum. 2004;455456:290-4.

8. Zhou JM, Andersson M. Machinability of abrasion resistance cast iron with pcBN cutting tools. Mater Manuf Process. 2008;23:506-12.

9. Chen L, Zhou J, Bushlya V, Gutnichenko O, Stahl J-E. Performance assessment of $\mathrm{pcBN}$ and $\mathrm{bcBN}$ tools in machining of high-chromium white cast iron. Int J Adv Manuf Technol. 2015;79(1-4):635-44.

10. Chen L, Stahl J-E, Zhao W, Zhou J. Assessment on abrasiveness of high chromium cast iron material on the wear performance of pcBN cutting tools in dry machining. J Mater Process Technol. 2018;255:110-20.

11. Meyer R, Köhler J, Denkena B. Influence of the tool corner radius on the tool wear and process forces during hard turning. Int J Adv Manuf Technol. 2012;58:933-40.

12. Gaitonde VN, Karnik SR, Figueira L, Davim JP. Performance comparison of conventional and wiper ceramic inserts in hard turning through artificial neural network modeling. Int J Adv Manuf Technol. 2010;52(1-4):101-14.

13. Silva AE, Melo INR, Pinheiro IP, Silva LR. Characterisation and machinability of high chromium hardened white cast iron with and without the addition of niobium. Wear. 2020;460461:203463.

14. ASTM: American Society for Testing and Materials. ASTM A-532/A-532M: standard specification for abrasion-resistant cast irons. West Conshohocken: ASTM; 1999

15. Diniz AE, Oliveira AJ. Hard turning of interrupted surfaces using CBN tools. J Mater Process Technol. 2008;195(1-3):275-81.

16. Oliveira AJ, Diniz AE, Ursolino DJ. Hard turning in continuous and interrupted cut with pcBN and whisker-reinforced cutting tools. J Mater Process Technol. 2009;209:5262-70.

17. Tabrett CP, Sare IR. The effect of heat treatment on the abrasion resistance of alloy white irons. Wear. 1997;203-204:206-19.

18. Maja, M.E., Maruma, M.G., Mampuru, L.A., Moema, S.J. Effect of niobium on the solidification structure and properties of hypoeutectic high-chromium white castirons. J S Afr Inst Min Metall. 2016;116:981-6.

19. Chung RJ, Tang X, Li DY, Hinckley B, Dolman K. Microstructure refinement of hypereutectic high $\mathrm{Cr}$ cast irons using hard carbide-forming elements for improved wear resistance. Wear. 2013;301(1-2):695-706.

20. Ibrahim MM, El-Hadad S, Mourad M. Enhancement of wear resistance and impact toughness of as-cast hypoeutectic high chromium cast iron using niobium. Int J Cast Met Res. 2017;31:72-9.

21. Filipovic M, Kamberovic Z, Korac M, Gavrilovski M. Microstructure and mechanical properties of $\mathrm{Fe}-\mathrm{Cr}-\mathrm{C}-\mathrm{Nb}$ white cast irons. Mater Des. 2013;47:41-8.

22. Filipovic M, Kamberovic Z, Korac M, Jordovic B. Effect of niobium and vanadium additions on the as-cast microstructure and properties of hypoeutectic $\mathrm{Fe}-\mathrm{Cr}-\mathrm{C}$ alloy. ISIJ Int. 2013;53(12):2160-6.

23. Ortega-Cubillos P, Nannetti-Bernardini PA, Celso-Fredel M, Campos AR. Wear resistance of high chromium white cast iron for coal grinding rolls. Rev Fac Ing Univ Antioquia. 2015;76:134-42.

24. Powell GLF, Laird G. Structure, nucleation, growth, and morphology of secondary carbides in high chromium and CrNi white cast irons. J Mater Sci. 1992;27(1):29-35.

25. Higuera-Cobos OF, Dumitru FD, Mesa-Grajales DH. Improvement of abrasive wear resistance of the high chromium cast iron ASTM A-532 through thermal treatment cycles. Rev Fac Ing. 2016;25:93-103.

26. Zhi X, Xing J, Fu H, Xiao B. Effect of niobium on the as-cast microstructure of hypereutectic high chromium cast iron. Mater Lett. 2008;62(6-7):857-60.

27. Çetinkaya C. An investigation of the wear behaviours of white cast irons under different compositions. Mater Des. 2006;27(6):437-45.

28. Poulachon, G., Moisan, A., Jawahir, I. S. Tool-wear mechanisms in hard turning with polycrystalline cubic boron nitride tools. Wear. 2001;250(1-12):576-86.

29. Yallese M, Chaoui K, Zeghib N, Boulanouar L, Gigal JF. Hard machining of hardened bearing steel using cubic boron nitride tool. J Mater Process Technol. 2009;209(2):1092-104. 
30. Chen H-X, Chang Z-C, Lu J-C, Lin H-T. Effect of niobium on wear resistance of $15 \% \mathrm{Cr}$ white cast iron. Wear. 1993;166:197-201.

31. Li S, Chen T, Qiu C, Wang D, Liu X. Experimental investigation of high-speed hard turning by pcBN tooling with strengthened edge. Int J Adv Manuf Technol. 2017;92(9-12):3785-93.

32. Trent EM, Wright PK. Metal cutting. 4th ed. Oxford: ButterworthHeinemann; 2000.
33. Ravi AM, Murigendrappa SM, Mukunda PG. experimental and analytical based investigations on machinability of highchrome white cast iron using CBN tools. Trans Indian Inst Met. 2014;68(1):61-77.

34. Ren XJ, James RD, Brookes EJ, Wang L. Machining of high chromium hardfacing materials. J Mater Process Technol. 2001;115:423-9. 